Dynamic Causal Effects of Post-Migration Schooling on Labour Market Transitions

MARIE ALBERTINE DJUIKOM GUY LACROIX

Allier savoir et décision 


\title{
2018s-09
}

\section{Dynamic Causal Effects of Post-Migration Schooling on Labour Market Transitions}

\author{
Marie Albertine Djuikom, Guy Lacroix
}

\begin{tabular}{c}
\hline Série Scientifique \\
Scientific Series
\end{tabular}

\section{Montréal \\ Avril/April 2018}

(C) 2018 Marie Albertine Djuikom, Guy Lacroix. Tous droits réservés. All rights reserved. Reproduction partielle permise avec citation du document source, incluant la notice $\mathbb{C}$. Short sections may be quoted without explicit permission, if full credit, including $(\mathrm{C})$ notice, is given to the source.

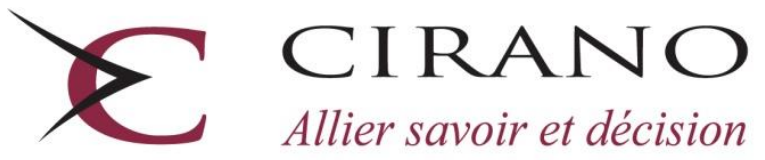

Centre interuniversitaire de recherche en analyse des organisations 


\section{CIRANO}

Le CIRANO est un organisme sans but lucratif constitué en vertu de la Loi des compagnies du Québec. Le financement de son infrastructure et de ses activités de recherche provient des cotisations de ses organisations-membres, d'une subvention d'infrastructure du gouvernement du Québec, de même que des subventions et mandats obtenus par ses équipes de recherche.

CIRANO is a private non-profit organization incorporated under the Quebec Companies Act. Its infrastructure and research activities are funded through fees paid by member organizations, an infrastructure grant from the government of Quebec, and grants and research mandates obtained by its research teams.

\section{Les partenaires du CIRANO}

\section{Partenaires corporatifs}

Autorité des marchés financiers

Banque de développement du Canada

Banque du Canada

Banque Laurentienne

Banque Nationale du Canada

Bell Canada

BMO Groupe financier

Caisse de dépôt et placement du Québec

Énergir

Hydro-Québec

Innovation, Sciences et Développement économique Canada

Intact Assurance

Investissements PSP

Ministère de l'Économie, de la Science et de l'Innovation

Ministère des Finances du Québec

Mouvement Desjardins

Power Corporation du Canada

Rio Tinto

Ville de Montréal

\section{Partenaires universitaires}

École de technologie supérieure

HEC Montréal

Institut national de la recherche scientifique

Polytechnique Montréal

Université Concordia

Université de Montréal

Université de Sherbrooke

Université du Québec

Université du Québec à Montréal

Université Laval

Université McGill

Le CIRANO collabore avec de nombreux centres et chaires de recherche universitaires dont on peut consulter la liste sur son site web.

Les cahiers de la série scientifique (CS) visent à rendre accessibles des résultats de recherche effectuée au CIRANO afin de susciter échanges et commentaires. Ces cahiers sont écrits dans le style des publications scientifiques. Les idées et les opinions émises sont sous l'unique responsabilité des auteurs et ne représentent pas nécessairement les positions du CIRANO ou de ses partenaires.

This paper presents research carried out at CIRANO and aims at encouraging discussion and comment. The observations and viewpoints expressed are the sole responsibility of the authors. They do not necessarily represent positions of CIRANO or its partners. 


\title{
Dynamic Causal Effects of Post-Migration Schooling on Labour Market Transitions*
}

\author{
Marie Albertine Djuikom ', Guy Lacroix
}

\begin{abstract}
Résumé/Abstract
Immigrants often experience diÿculties integrating the local labor market. In Canada, the govern-ment of Quebec implemented a program back in 1996 that explicitly selected highly qualified workers (Bachelors', Masters' or PhD's). This paper investigates the extent to which the return to foreign-acquired human capital is di erent from the education acquired in Quebec. Specifically, we seek to estimate the benefits of post-migration education over foreign-education on the transitions between qualified and un-qualified jobs and unemployment by means of a multiple-spells and multiple-states model. Our results indicate that immigrants originating from well-o countries have no need to further invest in domestic education. On the other hand, immigrants from poorer countries, despite being highly qualified, benefit greatly from such training in the long run as it eases their transitions into qualified and unqualified jobs and out of unemployment. Our results also indicate that selection into domestic education needs to be accounted for to avoid significant selection problems.
\end{abstract}

Mots clés/Keywords: Post-migration Schooling; Foreign Education; Labour Market Histories; Multiple-spells Multiple-states Models

Codes JEL/JEL Codes: C31; C41; J15; J24; J64; J61

\footnotetext{
* We are grateful to seminar participants at the 2016 Canadian Economics Association Meeting in Ottawa, the 2016 QICSS' Young Researchers Conference, Montreal, and the 2015 Société canadienne de science économique meeting in Montreal for comments and lively discussions.

† PhD Candidate, Department of economics, Université Laval, Canada.

$\$$ Department of economics, Université Laval, CRREP, IZA and CIRANO, Canada
} 


\section{Introduction}

Migrants often experience difficulties integrating the labor market in most host countries. In particular, they encounter difficulties finding a qualified job, i.e. one that corresponds to their level of schooling prior to migrating. In Canada, previous studies have found that the professional integration of migrants has worsened over time and that the wage gap with the natives has grown over the last decade. ${ }^{1}$ These results are surprising given that recent cohorts are highly educated, have French or English as their native language, and have had valuable work experience prior to migrating.

In Canada, migrants may be admitted under four separate categories skills-assessed principal applicants entering under the Federal Skilled Worker Program (independent economic immigrants), other economic immigrants, family class immigrants and refugees. The Skilled Worker Program is designed to identify applicants who are likely to become economically established upon migrating to Canada by weighing more heavily foreign acquired skills, work experience and knowledge of French or English, among other characteristics. The Province of Quebec has a separate set of criteria to select immigrants entering under the Skilled Worker Program. Quebec Skilled Workers applicants are thus not assessed based upon the selection factors of the Federal Skilled Worker Class. Not surprisingly, skills-assessed independent economic immigrants, both males and females, consistently have the highest median annual earnings among the four admission categories in the long run (Abbott and Beach, 2011; Sweetman and Warman, 2013), although other immigration classes fare just as well if not better in terms of employment. Yet, immigrants admitted under the Quebec Skilled Worker Program (QSWP) suffer from poorer recognition of foreign acquired skills than elsewhere in Canada. Many end-up working in occupations for which they are largely over-qualified (Lacroix, 2013). ${ }^{2}$

Analyzing the links between foreign-acquired skills and domestic labor market integration raises difficult empirical issues. First, most surveys do not distinguish between country of origin and country of study. Second, if foreign-acquired skills are indeed ill-recognized on the domestic market, then many may be induced to enhance their skills domestically, thus raising issues of endogeneity or self-selection into domestic education. In this study we avoid these issues in two ways. First, our unique dataset focuses on skilled immigrant workers and contains detailed information on their schooling and past work experience. We can thus separate out the "country of origin" from the "country of study" effects. Second, the data are rich enough to allow the estimation of the causal effect of post-migration education on the transitions between qualified

\footnotetext{
${ }^{1}$ Borjas (2000), Boudarbat and Boulet (2007), Grant (1999), Hansen (2000), Coulombe et al. (2014b,a).

${ }^{2}$ According to Coulombe et al. (2014a), the return to foreign education is intimately related to the level of development of one's birth country or country of study. Countries of origin of immigrants to Quebec and Canada differ substantially.
} 
and unqualified jobs and unemployment. Specifically, we estimate a multiple-states and multiplespells model which accounts for the endogeneity of the decision to invest in domestic education. Our identification strategy exploits the fact that the immigrants in our sample were selected under two sets of criteria. The majority of the sample was selected under a set that was in place between 1996 and 2006. A smaller subsample was selected under the new criteria that were implemented in 2006. These new criteria put more emphasis on language proficiency and work readiness, among other things. Our goal is to estimate the extent to which the new criteria expedited the transitions into employment, and the jobs constituted better matches to the workers' skills. If the latter holds, then we should observe fewer immigrants participating in domestic skill enhancing programs as get back to school.

Our approach extends the one proposed by Chesher and Lancaster (1983) and is loosely related to those considered in Uhlendorf and Zimmermann (2006) and Hansen (2000). In both cases, they investigate the determinants of the differentials in the duration of unemployment and employment spells between immigrants and natives in Germany and Sweden. Unlike these papers, our work focuses on the immigrants alone, not on a comparison between natives and immigrants. While it is widely acknowledged that the returns to education and work experience vary considerably between immigrants and natives, it has also been found that they vary greatly amongst immigrants (Coulombe et al., 2014a). A novel feature of our approach is to explicitly account for schooling quality of foreign-acquired skills. Following Coulombe et al. (2014b) and Chiswick and Miller (2007), we do this by proxying the quality by a function of the per capita GDP in the country of study.

The paper is organized as follows. Section 2 provides detailed informations on the data. Section 3.1 present a multiple-states and multiple-spells model which account for the endogeneity of investment in education. The effect of post-migration schooling is measured through a dummy variable which is set to one if the individual has attended school in Quebec and zero otherwise. In addition, the schooling status is treated a separate state in one version of the model. Our focus is on the education that leads to graduation from post-secondary education or more. We also estimate the model with schooling treated as exogenous and compare the parameter estimates with its endogenous variant. In Section 3.3, we discuss the quality of foreign schooling and how we proxy it. In addition, we present an empirical strategy to estimate the instantaneous probability of holding a qualified or unqualified job over time for each individual. This allows us to compare the employment trajectories for those who have attended school in Quebec relative to those who have not. This outcome is interesting from a policy perspective since it allows comparisons between individuals who differ in terms of characteristics such as country of study. Finally, Section 4 presents and discuss main results. We conclude the paper in Section 5. 


\section{Data and Preliminary Analysis}

Between January 2002 and December 2009, approximately 90,000 immigrants were admitted in through the Quebec Skilled Workers program. Our dataset is a random sample drawn from the so-called "landing file", a large administrative dataset managed by Immigration \& Citizenship Canada. ${ }^{3}$ The file contains all relevant pre-migration information such as highest degree schooling, results from language tests in French or/and English, the exact date of the entry in Canada, etc. The administrative information was complemented by a retrospective survey since arrival until May 2011 through which detailed information on all relevant periods of employment, unemployment, schooling, earnings, etc. are reported. Our sample contains 3,009 skilled immigrant workers. The retrospective survey was conducted conjointly by the Ministry of Immigration and Cultural Communities and the Ministry of Employment and Social Solidarity of the Quebec Government. According to Benzakour et al. (2013), the sample is representative of the population. Immigrants from Asia, and particularly those from the Middle-East, are however slightly under-represented in the sample. All other demographic characteristics (gender, marital status, educational background, etc.) are representative of the population. ${ }^{4}$

Most immigrants in our sample were selected according to the grid that was implemented in $1996(2,607 / 3,009)$ and remained constants until 2006. The remaining observations $(402 / 3,009)$ were selected on the basis of the October 2006 selection grid. The new grid weighs more heavily language proficiency (French and English), work experience and educational background. The new grid also introduced a Pass/Fail financial self-sufficiency contract. The "Contract respecting financial self-sufficiency" is a legal agreement by which the applicant undertakes to provide for his basic needs and, where applicable, those of his spouse and dependent children, for at least three months. The basic needs covered by this contract include food, housing, clothing and all other personal necessities. Failure to sign the contract leads to the automatic rejection of the application. This requirement implies that the applicants are not entitled to any public support (e.g., welfare) for at least three months upon landing.

Table 1 provides interesting insights into the characteristics of the sample. The table is divided by household type and selection grid. Thus, the sample consists of 1,552 couples and 1,457 singles. The first panel of the table shows that the applicants from the 2006 grid have a significantly higher level of education than those selected with the former grid. This is true for both couples and single people. Thus, the proportion of individuals with a master's or doctoral degree increased from about $17 \%$ to over $30 \%$. The proportion of individuals with secondary or lower education is the same for the two selection grids,

\footnotetext{
${ }^{3}$ This period corresponds to a significant increase in the proportion of immigrants in the population(Citizenship and Immigration Canada, 2014).

${ }^{4}$ See Benzakour et al. (2013) for a detailed discussion.
} 
Table 1: Sample Characteristics, by household type and Selection Grid

\begin{tabular}{|c|c|c|c|c|}
\hline \multirow{2}{*}{ Selection Grid } & \multicolumn{2}{|c|}{ Couples } & \multicolumn{2}{|c|}{ Singles } \\
\hline & 1996 & 2006 & 1996 & 2006 \\
\hline \multicolumn{5}{|l|}{ Education } \\
\hline Post-Secondart (\%) & 24.446 & 12.183 & 33.386 & 14.285 \\
\hline Bachelor $(\%)$ & 53.397 & 48.223 & 42.113 & 45.812 \\
\hline \multirow[t]{2}{*}{ Master-PhD (\%) } & 15.879 & 30.064 & 18.735 & 30.049 \\
\hline & \multicolumn{4}{|c|}{ GRID POINTS } \\
\hline \multicolumn{5}{|l|}{ Human Capital } \\
\hline Experience & 8.417 & 7.061 & 6.199 & 4.941 \\
\hline French proficiency & 12.774 & 12.624 & 14.421 & 14.517 \\
\hline English Proficiency & 3.725 & 4.305 & 3.884 & 4.527 \\
\hline Age & 7.689 & 16.173 & 9.319 & 17.626 \\
\hline \multicolumn{5}{|l|}{ Other Criteria } \\
\hline Past stay in Quebec & 0.640 & 1.741 & 1.797 & 2.857 \\
\hline Guaranteed Employment (\%) & 1.182 & 2.538 & 0.960 & 0.487 \\
\hline \multicolumn{5}{|l|}{ Spouse } \\
\hline Education & 2.696 & 2.147 & & \\
\hline Experience & 1.436 & 0.741 & & \\
\hline Age & 1.546 & 2.386 & & \\
\hline Children & 1.778 & 2.914 & & \\
\hline Number of observations & 1355 & 197 & 1252 & 205 \\
\hline
\end{tabular}

The second section of the table ("Grid Points") reports the scores obtained in each of the grids. Only the criteria common to the two grids are presented. The human capital criteria are relatively similar across the two grids, with the exception of English proficiency and age. In the latter case, the higher 2006 scores are mainly due to the fact that the average age of the applicants decreased in 2006, from 34 years to only 31.6. The selection of younger candidates has as a corollary a decrease in the score associated with experience. Likewise, the increase in points associated with English proficiency is partly due to an increased valuation in the 2006 grid (0-6 points) relative to the 1996 grid (0-3 points).

The "Other Criteria' section focuses on dimensions other than individual characteristics. For instance, the points allocated for previous stays in Québec were increased in the 2006 schedule. Points allocated for guaranteed employment were also increased in the 2006 grid. However, fewer than $1 \%$ of applicants had secured job prior to their arrival. ${ }^{5}$

The last section of the table relates to the spouses of the principal applicants. The points awarded to the spouse's schooling and experience were decreased in the 2006 grid. On the other hand, (younger) age and presence of children were awarded greater scores. This explains the

\footnotetext{
${ }^{5}$ Only 34 individuals had guaranteed employment on arrival. Of these, 28 had been selected with the 1996 grid and 6 had been selected with the 2006 grid.
} 
main differences between the mean values of the two grids.

From Table 1 it is readily apparent that individuals selected from the 2006 grid have more schooling and are younger. To the extent that these characteristics are more or less favourable to employment, one should expect to observe differences in the time required to find a job. Table 2 reports the elapse time between landing and finding a first job (column (1)) or a first which corresponds to qualification. Individuals who did not find employment at the time of the survey are excluded from the calculations in column (1). Those who had not yet found a suitable job are excluded from the calculations in column (2). ${ }^{6}$ The number of individuals Found in square brackets in each cell and that number is converted to a percentage and is shown in parentheses.

The time required to find a job is significantly lower for applicants selected using the 2006 grid. This is true for both single and couples, and regardless of whether the jobs corresponds to his qualification or not. In most cases, the time required has decreased between $50 \%$ and $66 \%{ }^{7}$ It is also found that singles are proportionally more likely to find a job (qualified or not) than couples. However, the proportion of employed individuals decreased slightly with the adoption of the 2006 grid. This is hardly surprising given that individuals selected using the 2006 grid arrived much later and have had consequently much less time to find a job. Like unattached individuals, proportionally fewer couples are employed in the 2006 grid sample. The gap between the employment rate of unattached individuals and couples remains at about 5 percentage points in both samples. With respect to the first skilled job, the differences observed between household types and samples are relatively similar to those observed for the first job.

The majority of the applicants succeed in finding a job. The time required to do so varies greatly between the different groups. Of particular concern is that most of them find it difficult to find a job whose requirements correspond to their academic skills. In fact, the table shows that $48.8 \%$ of single persons admitted under the 1996 grid have, after a long period of time, been able to find a job that corresponds to their skills. In addition, only $39.6 \%$ of couples admitted under the 2006 grid were able to do the same. It may be instructive to analyse the number of jobs that are filled before finding a first qualified one. Table 3 reports the sample frequencies of prior "unqualified jobs" by household type and selection grid. The first line of the table, "0", refers to the number of individuals whose first job was qualified. Thus, nearly $58 \%$ of the 1,233 individuals admitted under the 1996 grid were originally employed in a qualified job. As many as $75 \%$ of those admitted under the 2006 grid did the same. Better educated and younger workers under the 2006 grid, favourable economic conditions, etc. may all be partly responsible for the

\footnotetext{
${ }^{6}$ In other words, censored episodes are not included in the calculations.

${ }^{7}$ The average durations do not take censored observations into account. However, the calculation of the expected durations based on the survival curves, which takes censored episodes into account, nevertheless show that the expected duration for the sample of the single persons in the 1996 grid is 414.5 days whereas that of the sample of the 2006 grid is only 288.9 days. For couples, the results are 650.9 and 337.7 days, respectively.
} 
Table 2: Average Duration Between Landing and First Job, First Qualified Job, by Household Type and Selection Grid

\begin{tabular}{|c|c|c|c|c|}
\hline & \multicolumn{2}{|c|}{ First Job } & \multicolumn{2}{|c|}{ First Qualified Job } \\
\hline \multirow[t]{2}{*}{ Household type } & \multicolumn{2}{|c|}{ Grid } & \multicolumn{2}{|c|}{ Grid } \\
\hline & 1996 & 2006 & 1996 & 2006 \\
\hline \multirow[t]{3}{*}{ Singles } & 236.29 & 121.89 & 518.23 & 239.52 \\
\hline & {$\left[\begin{array}{ll}1 & 124\end{array}\right]$} & [180] & [611] & [96] \\
\hline & $(89.8 \%)$ & $(87.7 \%)$ & $(48.8 \%)$ & $(46.8 \%)$ \\
\hline \multirow[t]{3}{*}{ Couples } & 331.65 & 118.32 & 622.39 & 182.78 \\
\hline & {$\left[\begin{array}{ll}1 & 164\end{array}\right]$} & [161] & {$[569]$} & [78] \\
\hline & $(85.9 \%)$ & $(81.7 \%)$ & $(42.0 \%)$ & $(39.6 \%)$ \\
\hline \multirow[t]{3}{*}{ Total } & 284.81 & 120.21 & 568.46 & 214.09 \\
\hline & {$\left[\begin{array}{ll}2 & 288\end{array}\right]$} & [341] & {$\left[\begin{array}{ll}1 & 180\end{array}\right]$} & [174] \\
\hline & $(87.8 \%)$ & $(84.8 \%)$ & $(45.3 \%)$ & $(43.3 \%)$ \\
\hline Number of observations & 1355 & 197 & 1252 & 205 \\
\hline
\end{tabular}

differences between the two samples. Yet, over half of immigrants admitted under the Skilled Workers program never managed to find a job that corresponded to their qualifications. The large

Table 3: Number of jobs prior to finding a qualified one

\begin{tabular}{lcc|cc}
\hline Number of & \multicolumn{2}{c}{ Grid } & \multicolumn{2}{c}{ Household } \\
\cline { 2 - 5 } Unqualified Jobs & 1996 & 2006 & Singles & Couples \\
\hline 0 & 713 & 132 & 439 & 406 \\
& $(57.83)$ & $(74.58)$ & $(60.05)$ & $(59.10)$ \\
\cline { 2 - 5 } 1 & 266 & 27 & 145 & 148 \\
& $(21.57)$ & $(16.00)$ & $(19.84)$ & $(21.80)$ \\
\cline { 2 - 5 } 2 & 147 & 10 & 89 & 68 \\
& $(11.92)$ & $(5.65)$ & $(12.18)$ & $(10.01)$ \\
\cline { 2 - 5 } 3 & 71 & 8 & 38 & 41 \\
& $(5.76)$ & $(4.52)$ & $(5.20)$ & $(6.04)$ \\
4 & 36 & 0 & 20 & 16 \\
& $(2.92)$ & $(0.00)$ & $(2.74)$ & $(2.36)$ \\
\hline \multirow{2}{*}{ Total } & 1233 & 177 & 731 & 679 \\
\hline No Qualified Job & 1374 & 225 & 726 & 873 \\
& $(52.70)$ & $(55.97)$ & $(49.83)$ & $(56.25)$ \\
\hline
\end{tabular}

$\%$ between parentheses.

majority (90\%) of our sample was employed at one time between 2002-2011. As stressed above, half of them never managed to find a qualified job, others did so after transiting through a number of under-qualified jobs, and still others have gone through successive spells of employment and unemployment without ever finding a suitable job. The information in our dataset entitles us to identify four different statuses on the labour market: (1) Unqualified job; (2) Qualified job; (3) Unemployment; (4) Training. ${ }^{8}$ Table 4 reports the total number of transitions between the four

\footnotetext{
${ }^{8}$ In order to keep the model tractable, spells of concurrent employment and training are considered as training
} 
states over the period ranging from 2002 to 2011. The entire work history of 2,946 immigrants could be gathered from the data. According to the table, the 2,946 individuals in our sample experienced 11,788 spells over eight years, or approximately 4.0 per individual. Give that the yearly cohorts in our sample are about 375, it is likely that those who landed early witnessed yet many more transitions. Using the start and end dates of every employment spells, we can

Table 4: Transitions between labour market statuses

\begin{tabular}{|c|c|c|c|c|}
\hline Origin $\quad$ Destination & Unqualified job & Unemployment & Qualified job & Training \\
\hline Unqualified Job & $\begin{array}{c}\mathbf{9 5 5} \\
(32 \%)\end{array}$ & $\begin{array}{l}1,702 \\
(58 \%)\end{array}$ & $\begin{array}{c}82 \\
(3 \%)\end{array}$ & $\begin{array}{c}204 \\
(7 \%)\end{array}$ \\
\hline Unemployment & $\begin{array}{l}2,118 \\
(41 \%)\end{array}$ & $\begin{array}{c}\mathbf{9 2 1} \\
(17 \%)\end{array}$ & $\begin{array}{l}1,253 \\
(24 \%)\end{array}$ & $\begin{array}{c}927 \\
(18 \%)\end{array}$ \\
\hline Qualified Job & $\begin{array}{c}52 \\
(2 \%)\end{array}$ & $\begin{array}{c}833 \\
(41 \%)\end{array}$ & $\begin{array}{l}\mathbf{1 , 0 7 0} \\
(52 \%)\end{array}$ & $\begin{array}{c}93 \\
(5 \%)\end{array}$ \\
\hline Training & $\begin{array}{c}700 \\
(45 \%)\end{array}$ & $\begin{array}{c}383 \\
(24 \%)\end{array}$ & $\begin{array}{c}495 \\
(31 \%)\end{array}$ & $\begin{array}{c}0 \\
(0 \%)\end{array}$ \\
\hline
\end{tabular}

Number of Individuals:2,946; Number of spells: 11,788

calculate the daily employment rates for the immigrants of each selection grid and distinguish between qualified and unqualified jobs. Figure 1 focuses on the first three years upon landing. ${ }^{9}$

What the figure shows is that the employment rate of the latter is clearly higher than that of the applicants of the 1996 grid: their participation rate is higher both in skilled and unskilled jobs. It can also be seen that as of the second year upon landing, their participation rates in unskilled jobs falls rapidly and increases proportionately in skilled jobs. Nothing of the sort is observed for those who were selected using the 1996 grid. As stressed earlier, the 2006 group was both significantly more educated and younger than those from the 1996 group. ${ }^{10}$ It is not clear to what extent the observed differences in the employment dynamics of the two groups result from differences in human capital. It could be argued that younger and better skilled immigrants may find it yet even more difficult to find an adequate job. It may also be that some choose to invest in domestic education to facilitate their transition into employment. In order to net out the impact of Quebec-education from the foreign-human capital component, we must turn to a formal econometric model that accounts for potential selectivity in education.

spells. Treating them as a separate states would considerably increase the number of transitions and consequently the number of parameters to estimate.

${ }^{9}$ Those who were selected under the 2006 grid have at most a three-year history on the labour market.

${ }^{10}$ It should also be stressed that the 2006 group included proportionately fewer immigrants from the Maghreb, a region whose nationals experience more difficulties finding a job (Oreopoulos, 2011; Brière et al., 2017). 
Figure 1: Daily Participation rates, by Selection Grid, First Three Years

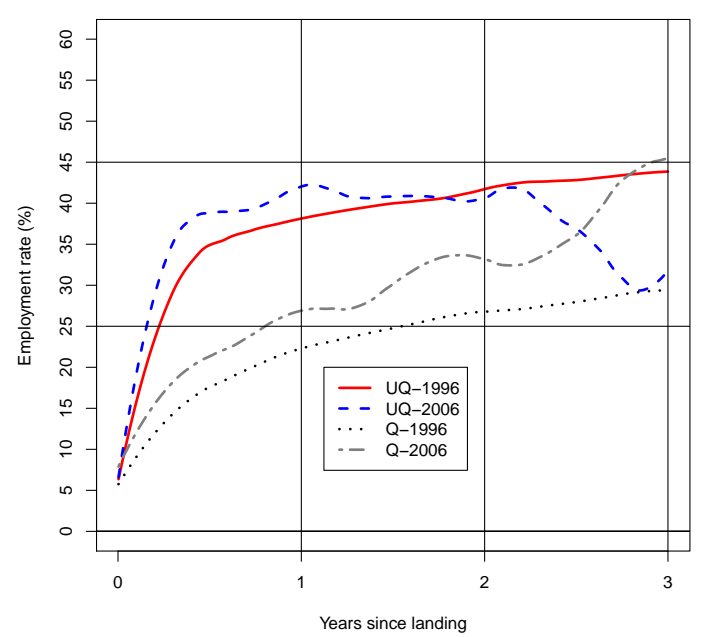

\section{Empirical Strategy}

The typical employment histories of two immigrants are depicted in Figure 2. Upon landing, they likely experience both a spell of unemployment. After a while, one may choose to accept an unqualified job (A) whereas the other may elect to invest in domestic education (B). ${ }^{11}$ Following his employment in an unqualified job, individual A may experience a new unemployment spell that lasts past the date of the survey (right censoring). Individual $\mathrm{B}$, on the other hand, may become unemployed following his graduation, after which he may find a qualified job that lasts past the survey date.

The previous section has stressed that the characteristics and the employment histories vary significantly across selection grids. Table 5 shows, on the other hand, that the individual characteristics of the Quebec-educated migrants and the foreign-educated migrants are relatively similar. Indeed, they more or less have the same age and the same level of proficiency in French and English. The proportion of females, of married couples and foreign work experience are almost identical across groups. They are also more likely to hold a bachelor's degree and less likely to hold a masters' or a PhD. Previous research has shown that those who hold a bachelor's degree don't perform as well on the labour market (Renaud, 2005; Lacroix, 2013). This is perhaps why they are more likely to back to school. Yet there are a few noteworthy differences. The first concerns the indicator of development. Recall that this indicator is given by the logarithm of the ratio between the home country GDP to the Canadian GDP (PPP). Thus Quebec-educated migrants originate on average from poorer countries than foreign-educated migrants. In addition,

\footnotetext{
${ }^{11}$ In the data, we do observed multiple job holding. We have chosen to give priority to the qualified job whenever a qualified and an unqualified jobs at held simultaneously. In such cases, an unqualified job starts once the qualified job has ended and ends whenever a (simultaneous) qualified job begins. When two jobs of the same type are held concurrently, we concatenate the durations into a single one.
} 
Figure 2: Employment History of Two Hypothetical Individuals
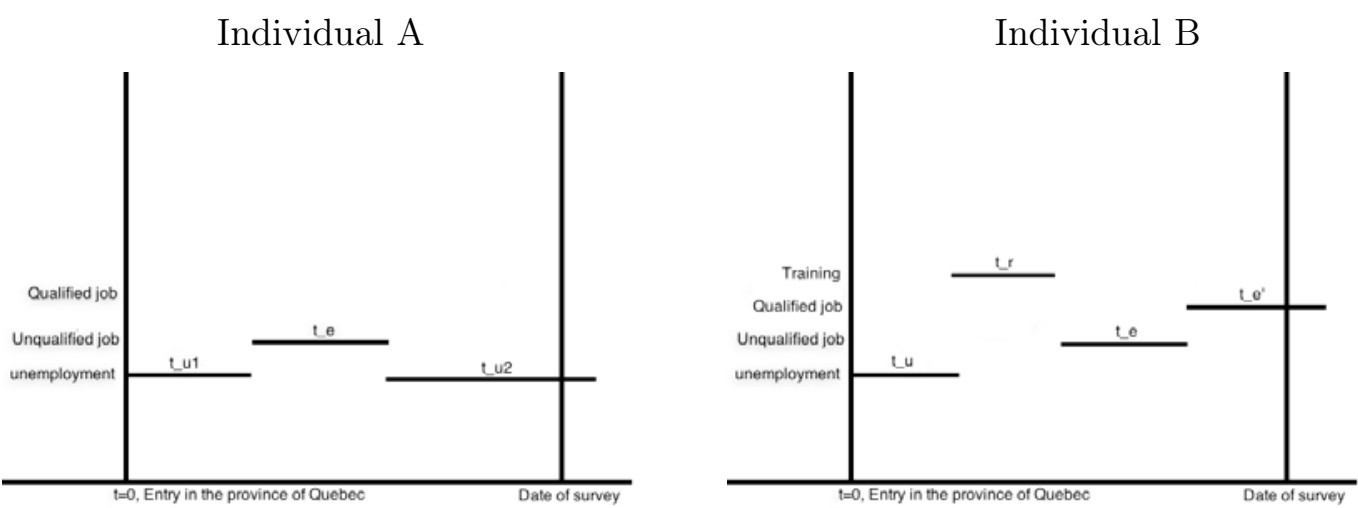

fewer Quebec-educated have had previous stays in Quebec prior to being granted the permanent resident status.

The bottom panel of the table reports the duration of the spells on the labour market. Note first that the Quebec-educated experience an increase in the duration of each state upon completing their education. The post-schooling average durations are almost identical to those of the foreign-educated migrants. Prior to their schooling, their employment duration is roughly half that of the foreign-educated, save for the unemployment spells which have more or less the same average duration. 
Table 5: Summary statistics of immigrants depending on whether or not they undergone training

\begin{tabular}{lcccccc}
\hline \hline & \multicolumn{3}{c}{ Trainees(1426) } & \multicolumn{3}{c}{ Non-Trainees(1533) } \\
\hline \multicolumn{1}{c}{ Variable } & Mean & Std. Dev. & \# Spells & Mean & Std. Dev. & \# Spells \\
\hline Age admission & 33.61 & 5.52 & - & 33.88 & 6.57 & - \\
Indicator of Devel. $\left(\ln \left(\frac{G D P^{\circ}}{G D P^{c}}\right)\right)$ & -1.80 & 1.23 & - & -1.21 & 1.22 & - \\
French & 13.78 & 3.14 & - & 13.57 & 3.75 & - \\
English & 3.38 & 1.85 & - & 3.84 & 1.84 & - \\
Female (\%) & 33.33 & - & - & 34.0 & - & - \\
Married (\%) & 50.42 & - & - & 52.44 & - & - \\
Previous stay in QC (\%) & 25.63 & - & - & 44.01 & - & - \\
Work experience (\%) & 82.7 & - & - & 84.65 & - & \\
Education & & & & & & - \\
$\quad$ Master/PhD (\%) & 15.06 & - & - & 22.79 & - & - \\
$\quad$ Bachelor (\%) & 52.87 & - & - & 44.66 & - & \\
$\quad$ Post sec/less (\%) & 32.07 & - & - & 32.54 & - & 1384 \\
Duration (in months) & & & & & & \\
Before training & & & & & & \\
$\quad$ Unqualified Job & 9.18 & 11.9 & 617 & 19.31 & 21.60 & \\
$\quad$ Unemployment & 6.88 & 9.85 & 1653 & 8.98 & 16.13 & \\
$\quad$ Qualified Job & 13.90 & 15.48 & 228 & 29.33 & 26.74 & \\
$\quad$ After training & & & & & & \\
$\quad$ Unqualified Job & 17.49 & 19.12 & 942 & & & \\
$\quad$ Unemployment & 12.08 & 16.90 & 983 & & & \\
$\quad$ Qualified Job & 21.82 & 20.13 & 698 & & & \\
\hline
\end{tabular}

\subsection{Econometric Model: Education as an Exogeneous Variable}

In order to model labour market history of our sample, we estimate a multiple spells-multiple states model with unobserved heterogeneity. Individuals are modelled as entering four distinct states : qualified job, unqualified job, unemployment and training. ${ }^{12}$. A qualified job is one which corresponds to an individual's educational degree at the time he received his permanent resident status. ${ }^{13}$

Let $k \in\left\{u, e, e^{\prime}\right\}$ index the states, where $u$ is unemployment, $e$ stands for employment in an unqualified job, and $e^{\prime}$ for employment in a qualified job. Denote the set of transitions by $K$, where $K=\left\{u e, u e^{\prime}, e u, e^{\prime} u\right\}$; the first letter denotes the origin state and the second stands for the destination state. Let $T_{k j}$ be a continuous random variable representing the duration of a spell in state $k$ that ends in state $j$. We thus have four random duration variables for each possible transitions, $T_{u e}, T_{u e^{\prime}}, T_{e u}$ and $T_{e^{\prime} u}$.

\footnotetext{
${ }^{12}$ We do not model the inactivity state because only six percent of individuals in our sample reported not seeking work for reasons of pregnancy, family problems, etc.

${ }^{13}$ The required level of education for each job is based on Statistics Canada's National Occupational Classification (NOC).
} 
The density function of $T_{j k}$ for a completed spell is defined as follows

$$
f_{j k}(t)=\lambda_{j k}(t) \times S_{j k}(t) \times S_{j h}(t), j \neq k \quad \text { and } \quad j \neq h
$$

and, $j, k, h=u, e, e^{\prime}$, where $\lambda_{j k}$ and $S_{j k}$ are respectively the hazard function and survival function of the exit from state $j$ to state $k$. We can write $f_{j k}(\cdot)$ conditional on individual-specific characteristics at time $t$, that is,

$$
\begin{aligned}
f_{j k}\left(t \mid X_{1}, X_{2}(t)\right)=\lambda_{j k}\left(t \mid X_{1}, X_{2}(t)\right) & \times \exp \left(-\int_{0}^{t} \lambda_{j k}\left(\tau \mid X_{1}, X_{2}(t)\right) d \tau\right) \\
& \times \exp \left(-\int_{0}^{t} \lambda_{j h}\left(\tau \mid X_{1}, X_{2}(t)\right) d \tau\right)
\end{aligned}
$$

$j \neq k$ and $j \neq h$. Here, $\lambda_{j k}\left(t \mid X_{1}, X_{2}(t)\right)$ is the probability of moving from state $j$ to state $k$ after $t$, conditional on not having left for either states $k$ and $h$ prior time $t$ and conditional on the fixed $\left(X_{1}\right)$ and time varying $\left(X_{2}(t)\right)$ individual characteristics.

The above specification must be modified to account for right censoring. In our data, every last spell is right censored at the time of the survey. The density function thus becomes:

$$
f_{j k}\left(t \mid X_{1}, X_{2}(t)\right)=\exp \left(-\int_{0}^{t} \lambda_{j k}\left(\tau \mid X_{1}, X_{2}(t)\right) d \tau\right) \times \exp \left(-\int_{0}^{t} \lambda_{j h}\left(\tau \mid X_{1}, X_{2}(t)\right) d \tau\right) .
$$

The likelihood function of a complete work history composed of $K_{i}$ spells is given by,

$$
\begin{aligned}
L_{i}\left(t_{s} ; s=1, \ldots, K_{i} \mid X_{1}, X_{2}\left(t_{s}\right)\right) & =\prod_{s=1}^{K_{i}} f_{j_{s} k_{s}}\left(t_{s} \mid X_{1}, X_{2}(t)\right. \\
& =\prod_{s=1}^{K_{i}}\left[\lambda_{j_{s} k_{s}}\left(t_{s} \mid X_{1}, X_{2}\left(t_{s}\right)\right)\right]^{1-c_{i_{s}}} \\
& \times \exp \left(-\int_{0}^{t_{s}} \lambda_{j_{s} k_{s}}\left(\tau \mid X_{1}, X_{2}\left(t_{s}\right)\right) d \tau\right) \\
& \times \exp \left(-\int_{0}^{t_{s}} \lambda_{j_{s} h_{s}}\left(\tau \mid X_{1}, X_{2}\left(t_{s}\right)\right) d \tau\right),
\end{aligned}
$$

where, $c_{i_{s}}=\left\{\begin{array}{cc}1 & \text { if spell } s \text { is right censored } \\ 0 & \text { Otherwise. }\end{array}\right.$

To illustrate, we can write the likelihood function of individual $A$ in Figure 2. He experiences three spells, starting with unemployment, and transiting successively into an unqualified job and then into another unemployment spell. The joint probability density for this hypothetical 
individual is given by,

$$
\begin{aligned}
L(t \mid X(t)) & =\lambda_{u e}\left(t_{u} \mid X_{1}, X_{2}\left(t_{u}\right)\right) \times \exp \left(-\int_{0}^{t_{u}} \lambda_{u e}\left(\tau \mid X_{1}, X_{2}\left(t_{u}\right)\right) d \tau\right) \times \\
& \exp \left(-\int_{0}^{t_{u}} \lambda_{u e^{\prime}}\left(\tau \mid X_{1}, X_{2}\left(t_{u}\right)\right) d \tau\right) \times \lambda_{e u}\left(t_{e} \mid X_{1}, X_{2}\left(t_{e}\right)\right) \times \\
& \exp \left(-\int_{0}^{t_{e}} \lambda_{e u}\left(\tau \mid X_{1}, X_{2}\left(t_{e}\right)\right) d \tau\right) \times \exp \left(-\int_{0}^{t_{u}} \lambda_{u e}\left(\tau \mid X_{1}, X_{2}\left(t_{u}\right)\right) d \tau\right) \times \\
& \exp \left(-\int_{0}^{t_{u}} \lambda_{u e^{\prime}}\left(\tau \mid X_{1}, X_{2}\left(t_{u}\right)\right) d \tau\right) .
\end{aligned}
$$

Each line represents the density of the duration in each state; as the last state is right-censored, the duration density is equal to the probability that this hypothetical individual remains in state $u$.

The likelihood function for the entire sample is as follows:

$$
L\left(t_{n} ; n=1, \ldots, K \mid X_{1}, X_{2}\left(t_{n}\right)\right)=\prod_{i=1}^{N} L_{i}\left(t_{s} ; s=1, \ldots, K_{i} \mid X_{1}, X_{2}\left(t_{s}\right)\right),
$$

with $K=\sum_{i=1}^{N} K_{i}$ and where $N$ corresponds to the number of individuals and $K_{i}$, the total number of spells for individual $i$.

\subsection{Education as an Endogenous Choice}

To the extent enrolling in some form of training is endogenous to the labour market status, it is necessary to modify the econometric specification accordingly. The endogeneity may arise from unobserved variables which are linked to the duration of unemployment and employment spells as well as the probability of being in a qualified or unqualified job.

In this framework, we must distinguish between four distinct states. The set of potential transitions includes the following nine possibilities, $K=\left\{e u, e r, u e, u e^{\prime}, u r, e^{\prime} u, r u, r e, r e^{\prime}\right\}$, where $r$ stands for training. The conditional density of moving from state $j$ to state $k$ at $t$ is given by,

$$
f_{j k}\left(t \mid X_{1}, X_{2}(t)\right)=\lambda_{j k}\left(t \mid X_{1}, X_{2}(t)\right) \times \prod_{k \neq j} \exp \left(-\int_{0}^{t} \lambda_{j k}\left(\tau \mid X_{1}, X_{2}(t)\right) d \tau\right),
$$

with $j, k=u, e, e^{\prime}, r$. The interpretation of the hazard function is the same as in the previous section. The likelihood for each individual is obtained by replacing the expression of density in equation (6) into equation (3). 


\subsection{Functional Form Specification}

In the literature, several probability density functions are customarily used to write the hazard function. Based on non-parametric analyses, both the Weibull and the log-logistic functional forms appear appropriate to our needs. However, in order to test the robustness of estimated parameters with respect to the functional form, we also estimate the model using a log-logistic density function.

The hazard function of transiting from state $j$ to state $k$ can be written as follows: ${ }^{14}$

$$
\begin{array}{lll}
\text { Weibull Distribution: } & \lambda_{j k}\left(t \mid X_{1}, X_{2}(t)\right)=\alpha_{j} t^{\left(\alpha_{j}-1\right)} \exp \left[X_{1} \beta_{j k}+X_{2}(t) \gamma_{j k}\right] \\
\text { Log Logistic Distribution : } & \lambda_{j k}\left(t \mid X_{1}, X_{2}(t)\right)=\frac{\alpha_{j} t^{\left(\alpha_{j}-1\right)} \exp \left[X_{1} \beta_{j k}+X_{2}(t) \gamma_{j k}\right]}{1+t^{\alpha_{j}} \exp \left[X_{1} \beta_{j k}+X_{2}(t) \gamma_{j k}\right]}
\end{array}
$$

where $\beta_{j k}$ is the parameter of time invariant variables, which is allowed to vary across transitions. For instance, we allow the effect of the training status (dummy variable) to be different when an individual moves from unemployment to a qualified job and when he moves from unemployment to employment in an unqualified job. The vector $\gamma_{j k}$ captures the effect of the time-varying covariates. Furthermore, we assume that the shape parameter, $\alpha_{j}$ is origin-specific only. ${ }^{15}$

On the other hand, for the probability of employment or training after experiencing an unemployment spell, we assume that the shape parameter is different regarding the destination state. In the job search literature, the probability of employment depends on the probability of receiving an offer and the probability of accepting an offer, which in turn depends on the reservation wage. As shown in Section 2, few individuals get a qualified job after experiencing an unqualified job and vice versa. Thus we suspect that the parameter $\alpha$ will differ according on whether an individual moves from unemployment to a qualified job or to an unqualified one. This is also in line with the job search theory which stipulates that employers rely on the employment record as a signal of potential productivity (Lynch, 1986).

\subsection{Accounting for Human Capital Quality}

Previous studies have show that human capital quality explains a significant part of wage gap and employment history among immigrants. Following this literature, we proxy the human capital quality by the relative Gross Domestic Product (GDP) of the home country to that of the Canadian GDP. ${ }^{16}$ Let $H C Q_{i}$ stand for Human capital quality of immigrant $i$, and $G D P_{i}$

\footnotetext{
${ }^{14}$ For simplicity, the subscript for spells are omitted since only origin and destination states matter here.

${ }^{15} \mathrm{~A}$ value of $\alpha_{j}<1$ indicates that the failure rate decreases over time. This is often referred to as "duration dependance" in the literature. A value of $\alpha_{j}=1$ indicates that the failure rate is constant over time. The Weibull distribution thus reduces to an exponential distribution. Finally, a value of $\alpha_{j}>1$ indicates that the failure rate increases with time.

${ }^{16}$ In the literature, it has been found that the immigrants' human capital quality is closely related to the level of development of the country of origin.
} 
be the per capita GDP of the country where he obtained his highest diploma before getting his permanent residence status in Canada. Likewise, let $G D P_{C A N}$ represent the GDP per capita of Canada. Our indicator is giving by ${ }^{17}$ :

$$
H C Q_{i}=\ln \left(\frac{G D P_{i}}{G D P_{C A N}}\right)
$$

$H C Q_{i}$ is negative whenever the highest diploma was obtained in a country with lower level of development than Canada and positive otherwise. It is equal to zero for immigrants who have got their highest degree in Quebec and, therefore were already in Quebec before getting permanent resident status. In our sample, roughly $6 \%$ of immigrants obtained their highest degree in Quebec.

We introduce this variable as time-invariant and we try to measure its effect in two ways. First, we measure its direct and indirect effect on labour mobility. The indirect effect runs through the level of education. Secondly, we investigate to what extent the effect of foreigneducation could change regarding the level of $H C Q$. Formally, the total effect of HCQ, denoted $\Lambda_{H C Q}^{i, H C Q}$, is given by ${ }^{18}$ :

$$
\Lambda_{j k}^{i, H C Q}=\beta_{j k}^{h c q, d} H C Q_{i}+\beta_{j k}^{h c q, i d} H C Q_{i} \times S=H C Q_{i}\left(\beta_{j k}^{d}+\beta_{j k}^{h c q, i d} \times S\right),
$$

with $S$ standing for the level of education and the total effect of Education, denoted $\Upsilon_{j k}^{s, i}$ is given by:

$$
\Upsilon_{j k}^{s, i}=S_{i}\left(\beta_{j k}^{s, d}+\beta_{j k}^{s, i d} * H C Q_{i}\right)
$$

$\beta_{j k}^{s, i d}$ measures the effect of education in terms of quality whereas $\beta_{j k}^{s, d}$ captures the effect in terms of the level of education when an individual moves from state $j$ to state $k$. If $\beta_{j k}^{s, i d}$ and $\beta_{j k}^{s, d}$ have the same sign, it implies that the HCQ reduces the effect of the level of education since the $\log (\mathrm{HCQ})$ is negative for $90 \%$ of immigrants.

\subsection{Allowing for Unobserved Heterogeneity}

As mentioned previously, it is important to take into account the unobserved heterogeneity among immigrants. Heckman and Singer (1984) stresses that a wrongly specified functional form for the unobserved heterogeneity could seriously bias the parameter estimates. To overcome this issue, the unobserved heterogeneity is modelled as a weighted mixture of iid standard normal random variates. ${ }^{19}$ Hence, let $\omega_{j}$ represents the unobserved heterogeneity specific to state $j$. In

\footnotetext{
${ }^{17}$ GDP per capita for each country are drawn from World Bank data base.

${ }^{18}$ The subscripts $d$ and $i d$ stand for direct and indirect effects, respectively.

${ }^{19}$ Identification issues may arise when there are too many mass points, as show by Baker and Melino (2000).
} 
this setting, we assume that $\omega_{j}$ may be written as

$$
\omega_{j}=\phi_{j} \xi_{1}+\psi_{j} \xi_{2}
$$

where $\xi_{1}$ and $\xi_{2}$ are drawn from a standard normal distribution. To insure the model is identified, we impose a minimal set of restrictions on the loading factors, namely that $\psi_{e}=1$ and $\phi_{j}=1$, $\forall \mathrm{j} \in\left\{u, e^{\prime}, r\right\}$.

The hazard rate and the likelihood function for an individual $i$ are then given by:

$$
\begin{array}{r}
\lambda_{j k}\left(t \mid X_{1}, X_{2}(t), \omega_{j}\right)=\alpha_{j} t^{\alpha_{j}-1} \exp \left[X_{1} \beta_{j k}+X_{2}(t) \gamma_{j k}+\omega_{j}\right] \\
\widehat{L_{i}=} \frac{1}{M} \sum_{m=1}^{M} L_{i}\left(t \mid X_{1}, X_{2}(t), \omega_{j m}\right)
\end{array}
$$

where $L_{i}(\cdot)$ is the contribution of individual $i$ to the total likelihood and is defined as previously. Finally, the total log-likelihood that we will maximize is defined as follow:

$$
\widehat{\log L}=\sum_{i=1}^{N} \log \left[\frac{1}{M} \sum_{m=1}^{M} L_{i}\left(t \mid X_{1}, X_{2}(t), \omega_{j m}\right)\right]
$$

$M$ is the size of vector $\xi_{1}$ and $\xi_{2}$. The maximization of the simulated likelihood function yields consistent and efficient parameter estimates whenever $\frac{\sqrt{N}}{M} \longrightarrow 0$ when $N \longrightarrow \infty$ and $H \longrightarrow \infty$ (see Gouriéroux and Monfort (1996, 1991); Brouillette and Lacroix (2011)). Although convergence is achieved when $M \geq 20$, we have chosen to set $M=100$. In this setting the correlation between states $j$ and $k$ is given by: ${ }^{20}$

$$
\operatorname{Corr}\left(\omega_{j}, \omega_{k}\right)=\frac{\phi_{j} \phi_{k}+\psi_{j} \psi_{k}}{\sqrt{\left(\phi_{j}^{2}+\psi_{j}^{2}\right)\left(\phi_{k}^{2}+\psi_{k}^{2}\right)}}
$$

\subsection{Expected Duration and Instantaneous Probability}

The sign of the parameter estimates indicates how the hazard function varies relative to a marginal change in a given variable. The interpretation of the size of the parameter is much more difficult to assess. These are best understood if we translate them into their marginal effect on the expected duration in a given state. By computing the expected duration in different states, we can then estimate the expected proportion of time an individual spends, conditional on his characteristics, in each state over a given period of time.

\footnotetext{
${ }^{20}$ The results using a fully non-parametric distribution function are available upon request. The main differences from our preferred specification are twofold: (1) Age do not affect the hazard rate while it does in the simulated likelihood and (2) the shape parameters, $\alpha$, all tend to be lower.
} 
Let $E D_{j}$ be the expected duration in state $j$ conditional on individual characteristics:

$$
E D_{j}=\frac{1}{M} \sum_{m=1}^{M} \times \int_{0}^{\infty} \tau f_{j}\left(\tau \mid X_{1}, X_{2}(t) ; \omega_{j m}\right) d \tau
$$

where $f_{j}(\cdot)$ is the density of the random duration variable in state $j$, conditional on individual characteristics, $X_{1}, X_{2}(t)$, when the destination state is unknown. Up to now, we have relied on the density function $f_{j k}(\cdot)$ rather than $f_{j}(\cdot)$. We must derive the density function $f_{j}(\cdot)$ from the densities $f_{j k}(\cdot), j, k=u, e, e, r$ and $j \neq k$. This can be achieved as follows:

$$
f_{j}\left(\iota_{j} \mid X_{1}, X_{2}(t), \omega_{j m}\right)=\frac{1}{M} \sum_{\substack { m=1 \\
\begin{subarray}{c}{h \in\left\{u, e, e^{\prime}, r\right\} \\
h, l, k \neq j{ m = 1 \\
\begin{subarray} { c } { h \in \{ u , e , e ^ { \prime } , r \} \\
h , l , k \neq j } }\end{subarray}}^{M} f_{j h}\left(\iota_{j} \mid X_{1}, X_{2}(t), \omega_{j m}\right),
$$

with $\iota_{j}=\min _{h}\left(T_{k h}\right), h \in\left\{u, e, e^{\prime}, r\right\}, h \neq k$.

As mentioned above, the expected duration is a relevant statistics since we can compute it for each state despite the fact that a given individual may not as yet spent time in a specific one.

Furthermore, it could be interesting to compute the instantaneous probability that an individual be observed in a particular state since landing (as in Figure 1). Let $D_{j}(t)$ be a dummy variable equal to 1 if the individual is in state $j$ at time $t$ and zero otherwise. The probability that an individual occupies a state $j$ at time $t$ is equal to the probability that at time $t-\delta t$ he is already in state $j$ and does not move to another state in $\delta t$ periods of time, plus the probability that he is in state $h, \quad h \neq j$ at time $t-\delta t$ and moves from $h$ to $j$ during the period of time $\delta t$. Formally, $P\left(D_{j}(t)=1\right)$ is given by ${ }^{21}$

$$
\begin{aligned}
P\left(D_{j}(t)=1\right)=P\left(D_{j}(t-\delta t)=1\right) \times \sum_{h \in\left\{u, e, e^{\prime}, r\right\}, h \neq j}\left(1-\lambda_{j h}(t) \partial t\right)+ \\
\sum_{h \in\left\{u, e, e^{\prime}, r\right\}, h \neq j} P\left(D_{h}(t-\delta t)=1\right) \times \lambda_{h j}(t) \partial t .
\end{aligned}
$$

To compute the instantaneous probability of each state we need to solve this first-order system of equations for $t .^{22}$

\section{Estimation Results and Discussion}

As mentioned above, we estimate two versions of the econometric model. The first one treats education as exogenous while the second treats it as endogenous. The model is estimated using

\footnotetext{
${ }^{21}$ For simplicity, the conditioning on observed individual characteristics is omitted.

${ }^{22}$ See Appendix A for the details of the derivation.
} 
both a Weibull and a Log-logistic specifications. For the sake of brevity only the results based on the Weibull specification are reported in the paper. ${ }^{23}$

\subsection{Education as an Exogenous variable}

Table 6 reports the parameter estimates when education is treated as exogenous. We define $Q C$-Education as a dummy variable that equals one if at any time since landing an individual attended school on a full-time basis. A number of interesting results emerge from the table. According to the parameter estimates, being educated in Quebec appears to have positive effects on labour market outcomes as it negatively impacts the transition rates into unemployment and out of employment. The new selection grid of 1996 has no impact on most transitions, save for the fact that it appears to have hastened the transition from unqualified employment into unemployment. Female immigrants are less likely to transit into employment (qualified or not) and thus spend more time unemployed than males.

Other results worthy of mention include all human capital variables. Having a foreign Master's or a $\mathrm{PhD}$ diploma, relative to a secondary degree, increases the duration of unemployment spells prior to obtaining a qualified job. On the other hand, the duration of qualified jobs, conditional on holding one, is longer for these highly qualified workers. Holding a bachelor degree has mixed effects on the labour market transitions. Although unqualified jobs tend to last longer, access to a qualified job is difficult for these workers. It is as if employers deem these workers as overqualified and are reluctant to offer them employment opportunities in line with their abilities. Having a high fluency score in French positively affects the transitions into employment. On the other hand, a high fluency score in English favours the transitions from unemployment into qualified jobs. Married immigrants experience longer employment spells, both qualified and unqualified.

\footnotetext{
${ }^{23}$ The results of the Log-logistics specification are available upon request.
} 
Table 6: Parameter Estimates: Exogenous Education

\begin{tabular}{|c|c|c|c|c|}
\hline Hazard functions & $\lambda_{e u}$ & $\lambda_{u e}$ & $\lambda_{u e^{\prime}}$ & $\lambda_{e^{\prime} u}$ \\
\hline QC-education & $-0.60 * * *$ & $0.25 * * *$ & $0.62 * * *$ & $0.14^{\dagger}$ \\
\hline 1996-Grid Reform & $0.39 * *$ & 0.10 & 0.17 & 0.23 \\
\hline Female & -0.04 & $-0.27 * * *$ & $-0.20 * *$ & -0.04 \\
\hline \multicolumn{5}{|l|}{ Foreign Education } \\
\hline Master or $\mathrm{PhD}$ & -0.12 & -0.05 & $-0.52^{* * *}$ & $-0.29^{*}$ \\
\hline Bachelor & $-0.31^{* * *}$ & 0.07 & $-0.78^{*}$ & -0.07 \\
\hline Fluency Score - French & 0.01 & $0.03^{* *}$ & $0.04^{* * *}$ & $0.02^{\dagger}$ \\
\hline Fluency Score - English & -0.03 & -0.002 & $0.09 * * *$ & 0.02 \\
\hline Married & $-0.16^{*}$ & -0.09 & 0.11 & $-0.16^{\dagger}$ \\
\hline $\mathrm{HCQ}$ & 0.04 & $0.12^{* * *}$ & $0.26^{* * *}$ & -0.05 \\
\hline $\mathrm{HCQ} \times$ Master or $\mathrm{PhD}$ & -0.11 & -0.06 & $-0.19^{*}$ & -0.08 \\
\hline HCQ $\times$ Bachelor & -0.07 & $-0.11^{*}$ & -0.05 & 0.07 \\
\hline Age at admission & $-0.15^{* * *}$ & $-0.11^{* * *}$ & $-0.14^{* * *}$ & $-0.22^{* * *}$ \\
\hline$(\text { Age at admission })^{2}$ & $0.002^{* * *}$ & $0.001^{* * *}$ & $0.002^{* * *}$ & $0.003^{* * *}$ \\
\hline Previous stay & $-0.24^{* *}$ & $-0.41^{* * *}$ & $0.28^{* * *}$ & $-0.53 * * *$ \\
\hline Experience & -0.17 & 0.06 & $0.31^{* * *}$ & -0.15 \\
\hline \multicolumn{5}{|l|}{ Landing Year(2002) } \\
\hline 2003 & & $0.24^{*}$ & 0.06 & \\
\hline 2004 & & $0.33^{* *}$ & 0.13 & \\
\hline 2005 & & $0.17^{\dagger}$ & -0.0 & \\
\hline 2006 & & 0.13 & -0.17 & \\
\hline 2007 & & $0.19 *$ & -0.01 & \\
\hline 2008 & & $0.21^{\dagger}$ & -0.08 & \\
\hline 2009 & & 0.16 & $-0.39^{*}$ & \\
\hline \multirow{10}{*}{$\begin{array}{l}\alpha \text { (Shape parameter) } \\
\phi_{e} \\
\psi_{u} \\
\psi_{e}^{\prime}\end{array}$} & \multicolumn{4}{|c|}{ Ancillary Parameters } \\
\hline & $0.86^{* * *}$ & $0.67 * * *$ & $0.67^{* * *}$ & $0.86^{* * *}$ \\
\hline & \multicolumn{4}{|c|}{$-0.23^{* *}$} \\
\hline & \multicolumn{4}{|c|}{$0.15^{* *}$} \\
\hline & \multicolumn{4}{|c|}{$-0.42^{* * *}$} \\
\hline & \multicolumn{4}{|c|}{ Correlation Matrix } \\
\hline & & $\omega_{e}$ & $\omega_{u}$ & $\omega_{e}^{\prime}$ \\
\hline & $\omega_{e}$ & - & -0.075 & -0.585 \\
\hline & $\omega_{u}$ & -0.075 & - & 0.853 \\
\hline & $\omega_{e}^{\prime}$ & -0.585 & 0.853 & - \\
\hline
\end{tabular}

Conditioning on the quality of foreign education (HCQ) yields interesting results. Indeed, immigrants originating from high-income countries (relative to Canada) have shorter unemployment spells and faster transition into qualified and unqualified jobs. On the other hand, the relative level of development has no impact on the duration of employment spells. Having experienced a previous stay in the province is perhaps the main factor that explains the dynamics of the labour market transitions. Indeed, this variable alone is responsible longer employment spells, both qualified and unqualified, but also longer and shorter unemployment spells that end in unqualified and qualified jobs, respectively.

Recall that the shape parameter, $\alpha_{j}$, indicates how the hazard rate in state $j$ varies with the duration. The parameter estimates reported in Table 6 are all below one which implies negative duration dependence. In other words, the longer one remains in a given state the less likely he/she will exit the state. More interestingly, the parameters that govern the unobserved 
heterogeneity are all statistically significant (see equation (8)). These can be expressed in terms of correlation between labour market states (equation (10)). According to the table, individuals who experiment short unqualified jobs tend to have long qualified job spells. Likewise, those who experiment short unemployment spells have shorter than average qualified job spells, but slightly longer than average unqualified job spells (although the correlation is relatively weak in the latter case.) These results suggest that those who transit across the two employment states may have different unobserved characteristics.

\subsection{Endogenous Education}

Table 7 reports the parameter estimates of a model in which education is a separate state. Its endogeneity is captured through the correlations with the alternative states. The table is set-up in a similar fashion to Table 6 except for addition of two variables:

1. QC-Education 1 is a dummy variable equal to one if a domestic diploma was granted just prior to the current spell.

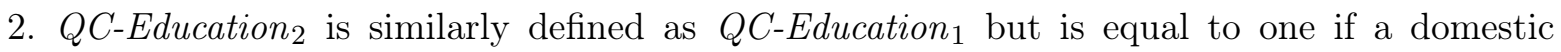
diploma was granted at least two spells prior to the current one.

A comparison between Tables 6 and 7 underlines the importance of treating domestic education as a choice variable. To begin with, obtaining a diploma in the near past ( $Q C$-Education 1 ) is now associated with much longer employment and unemployment spells. This is not surprising given that those who invest in domestic education do so soon upon landing. They thus have little work experience and must face the usual school-to-work transition hurdles. Those who elect not to invest in domestic education have gone through many more transitions on the labour market and have thus accumulated more experience. Fortunately, the beneficial effect of domestic education on employment duration does not taper off ( $Q C$-Education $\left.{ }_{2}\right)$ whereas the negative impact on unemployment duration either vanishes. Distant education also tend to expedite the duration of unemployment spells prior to landing a qualified job. The impact of education is thus relatively complex and can only be ascertained by turning to numerical simulations, as in the next section. The remaining estimates of the slope parameters are qualitatively similar to those of Table 6, save for a few who gain or lose statistical significance. Note however that, contrary to the results of the previous table, a higher HCQ now translates into longer employment spells. Not surprisingly, it is also found that a higher HCQ will lead to fewer transitions into training.

Yet small changes in these parameters may have important consequences on the labour market dynamics. This is investigated below. On the other hand, all ancillary parameters witness important changes. This is to be expected from treating education as an endogenous variable. As in the exogenous specification, their impact on the dynamics will be investigated through numerical simulations. 
Most hazard functions exhibit negative duration dependence as most the shape parameters reported in the table are below one. Interestingly, the transition rates between unemployment and schooling is constant $(\alpha=0.92)$. This implies that the probability of entering formal education, conditional on being unemployed, is independent of the duration of the spell. As in Table 6, the bottom panel presents the implicit correlation coefficients between the various states considered in the model. The most noteworthy feature of the table concerns the correlations with the schooling duration $\left(\omega_{r}\right)$. Individuals with unobserved characteristics that are favourable to long unemployment spells with also have longer than average schooling durations. Likewise, those with long qualified jobs will tend to have longer than average schooling durations. This is consistent with the idea that some have frequent short spells, while other have fewer but longer spells in each state. 
Table 7: Parameter Estimates: Endogenous Education

\begin{tabular}{|c|c|c|c|c|c|c|}
\hline Hazard functions & $\lambda_{e u}$ & $\lambda_{e r}$ & $\lambda_{u e}$ & $\lambda_{u e^{\prime}}$ & $\lambda_{u r}$ & $\lambda_{e^{\prime} u}$ \\
\hline QC-education 1 & $-0.69^{* * *}$ & & $-1.12^{* * *}$ & $-1.36^{* * *}$ & & $-0.67^{* * *}$ \\
\hline QC-education $_{2}$ & $-0.71 * * *$ & & -0.11 & $0.36^{* * *}$ & & $-0.53 * * *$ \\
\hline 1996-Grid Reform & $0.30^{*}$ & 0.37 & 0.22 & $0.37^{*}$ & -0.17 & 0.23 \\
\hline Female & -0.005 & 0.041 & $-0.23^{* *}$ & $-0.14^{\dagger}$ & $-0.25^{*}$ & 0.09 \\
\hline \multicolumn{7}{|l|}{ Foreign Education } \\
\hline Mast-PhD & -0.17 & 0.09 & 0.005 & $-0.53^{* * *}$ & -0.19 & $-0.29^{\dagger}$ \\
\hline Bachelor & $-0.27^{\dagger}$ & 0.29 & 0.15 & $-0.78^{* * *}$ & -0.10 & -0.15 \\
\hline Fluency Score - French & 0.015 & 0.034 & $0.034^{* *}$ & $0.052^{* * *}$ & $0.03^{\dagger}$ & $0.029^{\dagger}$ \\
\hline Fluency Score - English & -0.016 & -0.007 & -0.013 & $0.086^{* * *}$ & -0.036 & 0.002 \\
\hline Married & -0.13 & -0.14 & $-0.14^{*}$ & $0.15^{\dagger}$ & -0.034 & -0.17 \\
\hline $\mathrm{HCQ}$ & 0.02 & $-0.22^{\dagger}$ & $0.14^{* *}$ & $0.33^{* * *}$ & -0.02 & $-0.11^{\dagger}$ \\
\hline HCQ $\times$ Master-PhD & -0.010 & 0.11 & -0.05 & $-0.27^{* *}$ & -0.09 & -0.04 \\
\hline HCQ $\times$ Bachelor & -0.03 & 0.08 & -0.08 & -0.064 & -0.075 & 0.02 \\
\hline Age at admission & $-0.16^{* * *}$ & $-0.31^{* * *}$ & $-0.12^{* * *}$ & $-0.15^{* * *}$ & $-0.17^{* * *}$ & $-0.22^{* * *}$ \\
\hline$(\text { Age at admission })^{2}$ & $0.002^{* * *}$ & $0.004^{* * *}$ & $0.001^{* * *}$ & $0.0017^{* * *}$ & $0.0015^{* * *}$ & $0.0031^{* * *}$ \\
\hline Previous stay & $-0.29 * *$ & -0.04 & $-0.40 * * *$ & $0.32^{* * *}$ & $-0.28^{*}$ & $-0.50 * * *$ \\
\hline Experience & -0.06 & -0.24 & 0.06 & $0.35^{* * *}$ & 0.098 & -0.09 \\
\hline \multicolumn{7}{|l|}{ Landing Year (2002) } \\
\hline 2003 & & & $0.23^{*}$ & -0.09 & & \\
\hline 2004 & & & 0.18 & -0.02 & & \\
\hline 2005 & & & $0.26^{*}$ & $-0.27^{*}$ & & \\
\hline 2006 & & & 0.15 & $-0.34^{* *}$ & & \\
\hline 2007 & & & 0.11 & $-0.23^{\dagger}$ & & \\
\hline 2008 & & & -0.06 & $-0.44^{* *}$ & & \\
\hline \multirow[t]{2}{*}{2009} & & & -0.034 & $-0.57^{* *}$ & & \\
\hline & \multicolumn{6}{|c|}{ Ancillary Parameters } \\
\hline Shape parameter $(\alpha)$ & $0.85^{* * *}$ & $0.85^{* * *}$ & $0.66^{* * *}$ & $0.63^{* * *}$ & $0.92^{* * *}$ & $0.88^{* * *}$ \\
\hline$\phi_{e}$ & \multicolumn{6}{|c|}{-0.05} \\
\hline$\psi_{u}$ & \multicolumn{6}{|c|}{$-0.18^{* *}$} \\
\hline$\psi_{e}^{\prime}$ & \multicolumn{6}{|c|}{$-0.59 * * *$} \\
\hline \multirow[t]{7}{*}{$\psi_{r}$} & \multicolumn{6}{|c|}{-0.0053} \\
\hline & \multicolumn{6}{|c|}{ Correlation Matrix } \\
\hline & & $\omega_{e}$ & $\omega_{u}$ & $\omega_{e}^{\prime}$ & $\omega_{r}$ & \\
\hline & $\omega_{e}$ & - & 0.130 & -0.549 & -0.057 & \\
\hline & $\omega_{u}$ & 0.130 & - & 0.757 & 0.983 & \\
\hline & $\omega_{e}^{\prime}$ & -0.549 & 0.757 & - & 0.866 & \\
\hline & $\omega_{r}$ & -0.057 & 0.983 & 0.866 & - & \\
\hline
\end{tabular}

${ }^{\dagger} p<0.1,{ }^{*} p<0.05,{ }^{* *} p<0.01,{ }^{* * *} p<0.001$

Notes:

1. QC-education 1 is an indicator variable equal to one if a diploma was obtained in the previous spell. QCeducation $_{2}$ is equal to one if a diploma was granted at least two spells prior to the current one.

2. The transitions from education to employment or unemployment are also estimated in this specification. For the sake of brevity, they are not reported in the table but are available upon request.

\subsection{Expected Proportion of Time Spent in Each State}

The parameter estimates of Tables 6 and 7 capture fairly complex dynamics on the labour market. While their signs are easily interpreted, their marginal effects are not and are best understood by computing the expected proportion of time spent in each state, conditional on the values of the exogenous variables (see equation 11). Table 8 reports such proportions using the parameter estimates of Table 7. According to the model, the immigrants in our sample will 
spend roughly $68 \%$ of their time employed in qualified employment (women slightly less so). Recall that these individuals are highly qualified and most hold at least a bachelor's degree. Holding a domestic degree is associated with slightly more time spent unemployed, although the difference is relatively small. Having spent some time in Quebec in the past significantly reduced unemployment and increases time spent in a qualified job. From Table 7, holding a Master's or a $\mathrm{PhD}$ degree had a positive impact on the duration of both unemployment and employment spells. It turn out that holding such a degree is highly beneficial in terms of time spent employed in a qualified job and (little) time spent unemployed. Immigrants originating from Africa fare worst on the market and those from Europe fare best. ${ }^{24}$ The last lines of the table focus on the interactions between age and education. Interestingly, irrespective of the degree one holds, immigrating at a young age is highly beneficial. Thus youths with a post-secondary or less spend almost as much time employed in qualified jobs and out of unemployment as those with a bachelor's degree or above but who were admitted when above 30 years of age.

Table 8: Conditional Expected Proportion of Time in Each State

\begin{tabular}{|c|c|c|c|c|}
\hline \multicolumn{2}{|l|}{ Characteristics } & $\overline{P e}$ & $\overline{P_{u}}$ & $P P_{e^{\prime}}$ \\
\hline \multicolumn{2}{|l|}{ Overall } & 0.21 & 0.11 & 0.68 \\
\hline \multicolumn{2}{|l|}{ Male } & 0.21 & 0.1 & 0.69 \\
\hline \multicolumn{2}{|l|}{ Female } & 0.22 & 0.12 & 0.66 \\
\hline \multicolumn{2}{|l|}{ QC-education } & 0.22 & 0.12 & 0.66 \\
\hline \multicolumn{2}{|l|}{ Foreign-education } & 0.21 & 0.09 & 0.7 \\
\hline \multicolumn{2}{|l|}{ Previous stay in QC } & 0.19 & 0.07 & 0.74 \\
\hline \multicolumn{2}{|l|}{ No Previous stay in QC } & 0.23 & 0.13 & 0.65 \\
\hline \multicolumn{2}{|l|}{ Master's or PhD degree } & 0.17 & 0.08 & 0.75 \\
\hline \multicolumn{2}{|l|}{ Bachelor's degree } & 0.23 & 0.11 & 0.66 \\
\hline \multicolumn{2}{|l|}{ Post-secondary less } & 0.22 & 0.12 & 0.67 \\
\hline \multicolumn{2}{|l|}{ Africa } & 0.24 & 0.15 & 0.62 \\
\hline \multicolumn{2}{|l|}{ Asia } & 0.21 & 0.11 & 0.68 \\
\hline \multicolumn{2}{|l|}{ America } & 0.2 & 0.11 & 0.69 \\
\hline \multicolumn{2}{|l|}{ Europe } & 0.2 & 0.08 & 0.72 \\
\hline \multirow{3}{*}{ Age at admission $\leq 29$} & Master's or PhD degree & 0.19 & 0.06 & 0.76 \\
\hline & Bachelor's & 0.24 & 0.07 & 0.69 \\
\hline & Post-secondary or less & 0.23 & 0.07 & 0.7 \\
\hline \multirow{3}{*}{ Age at admission $>29$} & Master's or PhD & 0.17 & 0.09 & 0.74 \\
\hline & Bachelor's & 0.22 & 0.12 & 0.66 \\
\hline & Post-secondary or less & 0.21 & 0.13 & 0.65 \\
\hline
\end{tabular}

An alternative way to highlight the main features of our model is to focus on the conditional probabilities of being observed in various states as time unfolds (see equation 12). These probabilities are reported in Figure 3. The left-hand side figure illustrates the probability of occupying

\footnotetext{
${ }^{24}$ The country-of-origin effect is mediated through the HCQ variables.
} 
either a qualified or an unqualified job according to whether the degree was obtained in Quebec or in the country of origin. As is readily apparent, the probability is higher for those who obtained their degree in their home country. This is somewhat surprising but reflects the dynamics that are implicit in the parameter estimates of Table 7. Conversely, holding an unqualified job is more likely for those who are trained in Quebec as opposed to those trained in their home country. The profiles are relatively smooth and are a good fit to the data reported in Figure 1. The figure on the right-hand side exhibits the probability of holding a qualified job according to the continent of origin (Europe or Africa) and the country where the degree was granted. The figure shows that immigrants from Europe are much more likely to hold a qualified job than those from Africa. Further, Europeans holding a degree from Quebec are less likely to hold such a job. Conversely, Africans are slightly more likely to hold a qualified job if they received their degree in Quebec. These figures indicate that the labour market dynamics are complex and intimately linked to observed (and unobserved) characteristics. Simple models of labour force participation are likely to miss much of the complex interactions between various states and choices made by immigrants as time unfolds.

Figure 3: Conditional probability to be in a particular state
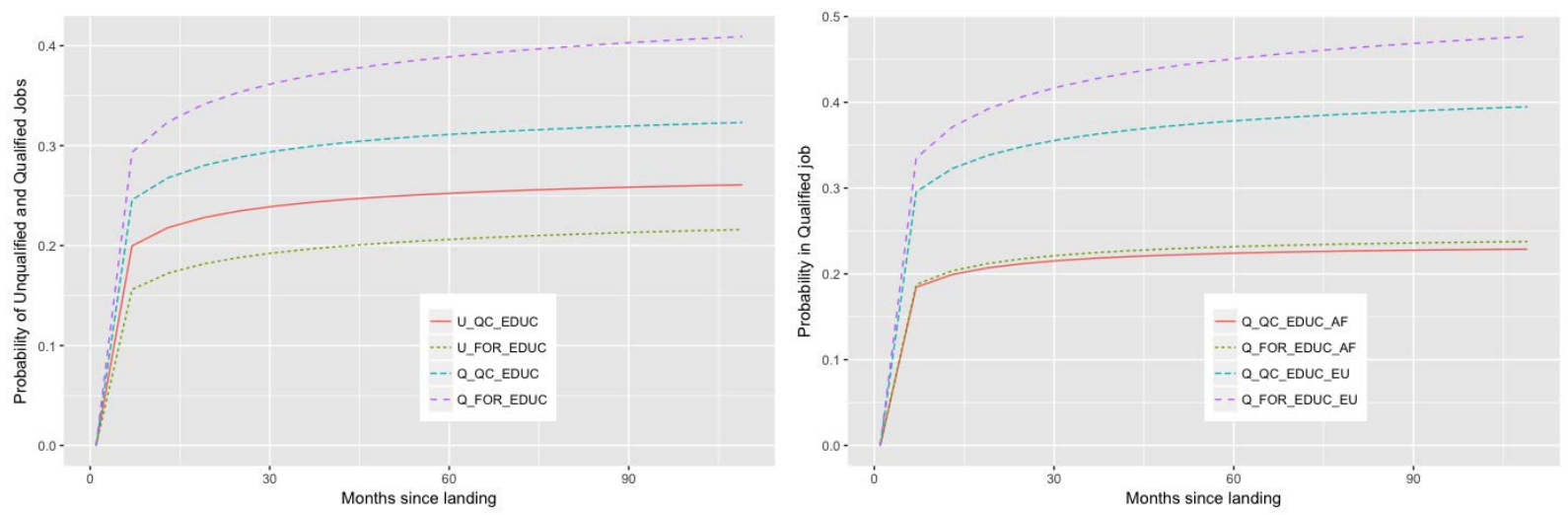

Note: Q QC-EDUC AF and Q QC-EDUC EU stand for "Qualified Job, Quebec diploma", from Africa and Europe, respectively. Q_Q $\mathbf{Q}$ _EDUC, $-\mathbf{U}$ _QC_EDUC, Q_FOR_EDUC and U_FOR_EDUC stand for qualified (Q) or unqualified (U) job with a Quebec $\left(\mathrm{QC}_{-}-\mathrm{EDUC}\right)$ or Foreing $\left(\overline{\mathrm{F} O R} \_\right.$EDUC) degree.

\section{Conclusion}

This paper investigates the labour market histories of highly qualified immigrants who landed in the Province of Quebec between 2002 and 2009. In particular, we focus on their transitions between qualified and unqualified employment, unemployment and investment in education. Our goal is to estimate the causal effects of schooling on the likelihood of finding a job that is suited to their abilities. Despite being highly qualified (Bachelor degrees and above), many immigrants experiment long spells of unemployment upon landing. Some are thus induced to undertake formal education to overcome the employment hurdle. Assuredly, a sizable fraction of 
this population manages to find adequate employment without resorting to domestic schooling. They are likely different from those who do, both from an observable and an unobservable point of view. In other words, domestic education is likely a choice variable whose endogeneity must be accounted for. Our results suggests that immigrants who graduated in Africa have a greater incentive to invest in domestic schooling since it increases their likelihood of holding both qualified and unqualified jobs over time.

Our results suggest that domestic schooling has a positive effect on the medium and long terms employment rates, but a negative one in the short term. In addition, immigrants who have spent some time in the province prior to receiving their permanent residence status also perform better on the labour market. This is perhaps why the provincial government has increased the weight it allocates to previous stays in its selection grids over time.

In recent years, the government of Quebec has selected highly educated immigrants in the hope that they would be more work ready. According to our results, those who hold either a Master's or a $\mathrm{PhD}$ degree need to wait longer to find a suitable job, but are also less likely to move back into unemployment once they are hired. The time spent in unemployment is virtually identical irrespective of the educational level. As pointed out by Renaud (2005) and Lacroix (2013), immigrants with a foreign bachelor's degree have a harder time finding a job that matches their skills. Since the majority of immigrants hold a bachelor's degree, $48 \%$ versus $19 \%$ for a Master's or $\mathrm{PhD}$, it may be advisable from a policy perspective to favour immigrants holding the latter.

Finally, we find that domestic schooling and labour market outcomes are intimately related through unobservable characteristics. This suggests that despite the richness of our data, unobserved factors play an important role in explaining labour market transitions. Assuredly, this makes designing appropriate policies quite challenging for policy-makers. 


\section{References}

Abbott, M. G., Beach, C. M., August 2011. Immigrant earnings differences across admission categories and landing cohorts in Canada. CLSRN, Working paper No. 81.1

Baker, M., Melino, A., 2000. Duration dependence and nonparametric heterogeneity: A monte carlo study. Journal of Econometrics 96 (2), 357-393. 14

Benzakour, C., Lechaume, A., Castonguay, M.-H., Santos, P., 2013. Enquête auprès des Immigrants de la Catégorie des Travailleurs Qualifiés. Portrait des répondants au moment de l'enquête. Québec, Ministère de l'Immigration et des communautés culturelles et mininstère de l'Emploi et de la Solidarité sociale, Gouvernement du Québec, 54p. 3

Blasco, S., Crépon, B., Kamionka, T., 2010. Evaluation of the Impact of Training on Individual Labor Market Transitions. Mimeo, Crest, Paris vol 44, No 4.

Borjas, G. J., 2000. Introduction to "Issues in the Economics of Immigration". NBER, 1-14. 1

Boudarbat, B., Boulet, M., 2007. Détérioration des salaires des nouveaux immigrants au Québec par rapport à l'Ontario et à la Comlombie-Britannique entre 1991 et 2007. IRRP Choix 13 n-7. Montréal: Institut de recherche en Politiques Publiques. 1

Brière, S., Fortin, B., Lacroix, G., 2017. Discrimination à l'embauche des candidates d'origine maghrébine dans la région de la capitale-nationale. Forthcoming, L'Actualité Économique. 7

Brouillette, D., Lacroix, G., 2011. Assessing the Impact of a Wage Subsidy for single parents on Social Assistance. Canadian Journal of Economics vol 44, No 4.15

Carrasco, R., Garcia Pérez, J. I., 2008. Unemployment duration among immigrants and natives: Unobserved heterogenéity in a multi-spell duration model. Working Paper. Economic 8 No 33.

Chesher, A., Lancaster, T., 1983. The Estimation of Models of Labour Market Behaviour. The Review of Economics Studies 50 (4), 609-624. 2

Chiswick, B. R., Miller, P. W., 2007. The International Transferability of Immigrants' Human Capital Skills. IZA Discussion Paper 2670. 2

Citizenship, Immigration Canada, 2014. Canada - Résidents permanents selon le sexe et la catégorie, 1989-2013. Statistiques Canada. 3

Cloutier, L., Benard, P., D.-G., T., 2009. Job Quality and Gender Inequality: Key Changes in Québec over the Last Decade. Studies in Social Justice 3, Issues 2, 191-212. 
Coulombe, S., Grenier, G., Nadeau, S., 2014a. Human Capital Quality and the Immigrant wage gap. IZA Journal of Migration 3. 1, 2

Coulombe, S., Grenier, G., Nadeau, S., 2014b. Quality of work experience and economic development-estimates using Canadian Immigrant data. Journal of Human Capital 8. 1, 2

Cox, D. R., 1972. Regression Models and Life-Tables. Journal of the Royal Statistical Society. Series B (Methodological) 34 No. 2, 187-220.

Esses, V., F., D. J., Jackson, L. M .and Armstrong, T. L., 2001. The Immigration Dilemma- The Role of Perceived group competition, ethnic prejudice, and national identity. Journal of Social Issues 57 No 3, 389-412.

Gouriéroux, C., Monfort, A., 1991. Simulation based econometrics in models with heterogeneity. Annales d'économie et de statistique. 15

Gouriéroux, C., Monfort, A., 1996. Simulation-based Econometric Methods. Oxford University Press. 15

Grant, M., 1999. Evidence of new Immigrant Assimilation in Canada. Canadian Journal of Economies 32 No 4, 930-955. 1

Green, D. A., Worswick, C., 2010. Entry earnings of immigrant men in canada: The roles of labour market entry effects and returns to foreign experience. Canadian immigration: Economic evidence for a dynamic policy environment, 77-110.

Gritz, R. M., 1993. The impact of training on the frequency and duration of employment. Journal of Econometrics 57, 21-51.

Hansen, J., 2000. The duration of Immigrants Unemployment Spells:evidence from Sweden. IZA Discussion Paper 155. 1, 2

Heckman, J., Ichimura, H., Smith, J., Todd, P., 1998. Characterizing Selection Bias Using Experimental Data. Econometrica 66 (05), 1017-1098.

Heckman, J., Singer, B., 1984. A method for Minimizing the Distribution Asumptions in Econometrics Models for Duration Data. Econometrics, 271-320. 14

Hirano, K., Imbens, G., Ridder, G., 2003. Efficient Estimation of Average Treatment Effets Using the Estimaed Propensity Score. Econometrica 71 (04), 1161-1189.

Imbens, G. W., Wooldridge, J. M., 2009. Recent Developments in the Econometrics of Program Evaluation. Journal of Economic Literature 47 (1), 5-86. 
Lacroix, G., 2013. L'intégration en emploi des immigrants de la catégorie des travailleurs qualifiés au québec, 2002-2009. https://www.mess.gouv.qc.ca/publications/pdf/ADMIN_ETQ_ 4.pdf. 1, 8, 24

Lynch, L. M., 1986. The Youth labor market in the 80s : Determinants of Re-employment probabilities for Young Men and Women. National, Bureau of Economic Research No 2021. 13

Oreopoulos, P., 2011. Why do skilled immigrants struggle in the labor market? A field experiment with thirteen thousand résumés. American Economic Review: Public Policy 3, 148-171. 7

Renaud, J., 2005. Limites de l' Accès à l' Intégration des Immigrants au Québec: Quelques exemples à partir d'enquêtes. Santé, Société at Solidarité No 1. 8, 24

Schaafsma, J., Sweetman, A., 2001. Immigrant Earnings: Age at Immigration Matters. The Canadian Journal of Economics 34 No 4.

Sweetman, A., 2004. Immigrant Source Country Educational Quality and Canadian Labour Market Outcomes Catalogue. Statistics Canada,Ottawa 234.

Sweetman, A., Warman, C., May 2013. Canada's immigration selection system and labour market outcomes. Canadian Public Policy 39, 141-160. 1

Uhlendorf, A., Zimmermann, K. F., 2006. Unemployment dynamics among migrants and natives. IZA,Institute for the Study of Labor 2299. 2 


\section{Appendix A. Proofs}

Correlation between unobserved heterogeneities

Taking the characterization of unobserved heterogeneity given in section 3.5, we have,

$$
\omega_{j}=\mu_{j}+\nu_{j} \theta^{*}
$$

where

$$
\theta^{*}=\left\{\begin{array}{llll}
\theta_{1} & \text { with } & \text { probability } & p_{1} \\
\theta_{2} & \text { with } & \text { probability } & p_{2} \\
\theta_{3} & \text { with } & \text { probability } & \left(1-p_{1}-p_{2}\right)
\end{array}\right.
$$

and $\operatorname{cov}\left(\omega_{j}, \omega_{k}\right)=\nu_{j} \nu_{k} \operatorname{var}\left(\theta^{*}\right), \operatorname{var}\left(\omega_{j}\right)=\nu_{j}^{2} \operatorname{var}\left(\theta^{*}\right)$. Therefore,

$$
\rho_{j k} \quad=\frac{\operatorname{cov}\left(\omega_{j}, \omega_{k}\right)}{\sigma_{j} \sigma_{k}}=\frac{\nu_{j} \nu_{k} \operatorname{var}\left(\theta^{*}\right)}{\sqrt{\nu_{j}^{2} \operatorname{var}\left(\theta^{*}\right)} \sqrt{\nu_{k}^{2} \operatorname{var}\left(\theta^{*}\right)}}=1
$$

Instantaneous probability

In the case where we have three states, that is $k \in e, u, e^{\prime}$, the instantaneous probability to be in state $k$ is given by,

$$
\begin{aligned}
P\left(D_{e^{\prime}}(t)=1\right)= & P\left(D_{e^{\prime}}(t-\delta t)=1\right) \times\left[1-\lambda_{e^{\prime} u}(t) \delta t\right]+P\left(D_{u}(t-\delta t)=1\right) \times \lambda_{u e^{\prime}}(t) \delta t \\
& +P\left(D_{r}(t-\delta t)=1\right) \times \lambda_{r e^{\prime}}(t) \delta t
\end{aligned}
$$

Arranging gives,

$$
\begin{array}{r}
\frac{P\left(D_{e^{\prime}}(t)=1\right)-P\left(D_{e^{\prime}}(t-\delta t)=1\right)}{\delta t}=-P\left(D_{e^{\prime}}(t-\delta t)=1\right) \times \lambda_{e^{\prime} u}(t) \\
+P\left(D_{u}(t-\delta t)=1\right) \times \lambda_{u e^{\prime}}(t)+P\left(D_{u}(t-\delta t)=1\right) \times \lambda_{r e^{\prime}}(t)
\end{array}
$$

Letting $\delta t$ pass to zero, we obtain,

$\frac{d P\left(D_{e^{\prime}}(t)=1\right)}{d t}=-P\left(D_{e^{\prime}}(t)=1\right) \times \lambda_{e^{\prime} u}(t)+P\left(D_{u}(t)=1\right) \times \lambda_{u e^{\prime}}(t)+P\left(D_{r}(t)=1\right) \times \lambda_{r e^{\prime}}(t)$ 
We get similar expression for $P\left(D_{e}(t)=1\right)$ in the same way, given by,

$$
\begin{aligned}
& P\left(D_{e}(t)=1\right)=P\left(D_{e}(t-\delta t)=1\right) \times\left[1-\lambda_{e u}(t) \delta t\right]\left[1-\lambda_{e r}(t) \delta t\right]+P\left(D_{u}(t-\delta t)=1\right) \times \lambda_{u e}(t) \delta t \\
& \quad+P\left(D_{r}(t-\delta t)=1\right) \times \lambda_{r e}(t) \delta t \\
& =P\left(D_{e}(t-\delta t)=1\right) \times\left[1-\lambda_{e u}(t) \delta t-\lambda_{e r}(t) \delta t+\lambda_{e r}(t) \lambda_{e u}(t) \delta t^{2}\right]+P\left(D_{u}(t-\delta t)=1\right) \times \lambda_{u e}(t) \delta t \\
& \quad+P\left(D_{r}(t-\delta t)=1\right) \times \lambda_{r e}(t) \delta t
\end{aligned}
$$

As before, we get:

$$
\begin{aligned}
\frac{d P\left(D_{e}(t)=1\right)}{d t}= & -P\left(D_{e}(t)=1\right) \times\left[\lambda_{e r}(t)+\lambda_{e u}(t)\right]+P\left(D_{u}(t)=1\right) \times \lambda_{u e}(t)+ \\
& -P\left(D_{r}(t)=1\right) \times \lambda_{r e}(t)
\end{aligned}
$$

Once again, we get similar expression for $P\left(D_{u}(t)=1\right)$ in the same way, given by,

$$
\begin{aligned}
P\left(D_{u}(t)=1\right)=P\left(D_{u}(t-\delta t)=1\right) \times\left[1-\lambda_{u e}(t) \delta t\right]\left[1-\lambda_{u e^{\prime}}(t) \delta t\right]\left[1-\lambda_{u r}(t) \delta t\right]+ \\
P\left(D_{e}(t-\delta t)=1\right) \times \lambda_{e u}(t) \delta t+P\left(D_{e}^{\prime}(t-\delta t)=1\right) \times \lambda_{e^{\prime} u}(t) \delta t+P\left(D_{r}(t-\delta t)=1\right) \times \lambda_{r u}(t) \delta t
\end{aligned}
$$

As before, by arranging and letting $\delta t$ tend to zero, we get:

$$
\begin{aligned}
\frac{d P\left(D_{u}(t)=1\right)}{d t}= & -P\left(D_{u}(t)=1\right) \times\left[\lambda_{u e}(t)+\lambda_{u e^{\prime}}(t)+\lambda_{e r}(t)\right]+P\left(D_{e}(t)=1\right) \times \lambda_{e u}(t) \\
& +P\left(D_{e}^{\prime}(t)=1\right) \times \lambda_{e^{\prime} u}(t)+P\left(D_{r}(t)=1\right) \times \lambda_{r u}(t)
\end{aligned}
$$

and ,

$$
\begin{aligned}
\frac{d P\left(D_{r}(t)=1\right)}{d t}= & -P\left(D_{r}(t)=1\right) \times\left[\lambda_{r e}(t)+\lambda_{r e^{\prime}}(t)+\lambda_{r u}(t)\right]+P\left(D_{e}(t)=1\right) \times \lambda_{e r}(t) \\
& +P\left(D_{e}^{\prime}(t)=1\right) \times \lambda_{e^{\prime} r}(t)+P\left(D_{u}(t)=1\right) \times \lambda_{u r}(t)
\end{aligned}
$$

As the results we have obtained the equation system:

$$
\left(\begin{array}{c}
\frac{d}{d t} P\left(D_{e^{\prime}}(t)=1\right) \\
\frac{d}{d t} P\left(D_{e}(t)=1\right) \\
\frac{d}{d t} P\left(D_{u}(t)=1\right) \\
\frac{d}{d t} P\left(D_{r}(t)=1\right)
\end{array}\right)=\left(\begin{array}{cccc}
A_{e^{\prime}}(t) & B_{e^{\prime}}(t) & C_{e^{\prime}}(t) & D_{e^{\prime}}(t) \\
B_{e}(t) & A_{e}(t) & C_{e}(t) & D_{e}(t) \\
B_{u}(t) & C_{u}(t) & A_{u}(t) & D_{u}(t) \\
B_{r}(t) & C_{r}(t) & D_{r}(t) & A_{r}(t)
\end{array}\right) \times\left(\begin{array}{c}
P\left(D_{e^{\prime}}(t)=1\right) \\
P\left(D_{e}(t)=1\right) \\
P\left(D_{u}(t)=1\right) \\
P\left(D_{r}(t)=1\right)
\end{array}\right)
$$


With,

$$
\left\{\begin{array}{l}
A_{e^{\prime}}(t)=-\lambda_{e^{\prime} u}(t) \\
B_{e^{\prime}}(t)=0 \\
C_{e^{\prime}}(t)=\lambda_{u e^{\prime}}(t) \\
D_{e^{\prime}}(t)=\lambda_{r e^{\prime}}(t) \\
A_{e}(t)=-\left(\lambda_{e u}(t)+\lambda_{e r}(t)\right. \\
B_{e}(t)=0 \\
C_{e}(t)=\lambda_{u e}(t) \\
D_{e}(t)=\lambda_{r e}(t) \\
A_{u}(t)=-\left(\lambda_{u e}(t)+\lambda_{u e^{\prime}}(t)+\lambda_{e r}(t)\right) \\
B_{u}(t)=-\lambda_{e^{\prime} u}(t) \\
C_{u}(t)=\lambda_{e u}(t) \\
D_{u}(t)=\lambda_{r u}(t) \\
B_{r}(t)=\lambda_{e^{\prime} r}(t) \\
C_{r}(t)=\lambda_{e r}(t) \\
D_{r}(t)=\lambda_{u r}(t) \\
A_{r}(t)=-\left(\lambda_{r e}(t)+\lambda_{r e^{\prime}}(t)+\lambda_{r u}(t)\right)
\end{array}\right.
$$

